\title{
Kaempferol inhibits angiogenic ability by targeting VEGF receptor-2 and downregulating the PI3K/AKT, MEK and ERK pathways in VEGF-stimulated human umbilical vein endothelial cells
}

\author{
HSIEN-KUO CHIN ${ }^{1}$, CHI-TING HORNG $^{2,3}$, YI-SHAN LIU ${ }^{4}$, CHI-CHENG LU $^{5}$, CHEN-YING SU $^{6}$, \\ PEI-SYUAN CHEN ${ }^{7}$, HONG-YI CHIU ${ }^{5}$, FUU-JEN TSAI ${ }^{8-10}$, \\ PO-CHUEN SHIEH ${ }^{7}$ and JAI-SING YANG ${ }^{11}$ \\ ${ }^{1}$ Department of Surgery and ${ }^{2}$ Medical Education Center, Kaohsiung Armed Forces General Hospital, Kaohsiung 80284; \\ ${ }^{3}$ Institute of Biochemistry and Biotechnology, Chung Shan Medical University, Taichung 40201; \\ ${ }^{4}$ Department of Dermatology, E-Da Hospital and I-Shou University, Kaohsiung 82445; \\ ${ }^{5}$ Department of Pharmacy, Buddhist Tzu Chi General Hospital, Hualien 97002; \\ Departments of ${ }^{6}$ Nursing and ${ }^{7}$ Pharmacy, Tajen University, Pingtung 90741 ; \\ ${ }^{8}$ Huamn Genetics Center, Department of Medical Research and \\ ${ }^{9}$ Department of Medical Genetics, China Medical University Hospital, Taichung 40447; \\ ${ }^{10}$ School of Chinese Medicine, China Medical University, Taichung 40402; \\ ${ }^{11}$ Department of Medical Research, China Medical University Hospital, \\ China Medical University, Taichung 40447, Taiwan, R.O.C.
}

Received October 17, 2017; Accepted March 9, 2018

DOI: $10.3892 / o r .2018 .6312$

\begin{abstract}
Anti-angiogenesis is one of the most general clinical obstacles in cancer chemotherapy. Kaempferol is a flavonoid phytochemical found in many fruits and vegetables. Our previous study revealed that kaempferol triggered apoptosis in human umbilical vein endothelial cells (HUVECs) by ROS-mediated p53/ATM/death receptor signaling. However, the anti-angiogenic potential of kaempferol remains unclear and its underlying mechanism warranted further exploration in VEGF-stimulated HUVECs. In the present study, kaempferol significantly reduced VEGF-stimulated HUVEC viability. Kaempferol treatment also inhibited cell migration, invasion, and tube formation in VEGF-stimulated HUVECs. VEGF receptor-2 (VEGFR-2), and its downstream signaling cascades (such as AKT, mTOR and MEK1/2-ERK1/2) were reduced as
\end{abstract}

Correspondence to: Dr Po-Chuen Shieh, Department of Pharmacy, Tajen University, 20 Weixin Road, Yanpu, Pingtung 90741, Taiwan, R.O.C.

E-mail: pochuen@tajen.edu.tw

Dr Jai-Sing Yang, Department of Medical Research, China Medical University Hospital, China Medical University, 2 Yude Road, North District, Taichung 40447, Taiwan, R.O.C.

E-mail: jaisingyang@gmail.com

Key words: angiogenesis, kaempferol, VEGF receptor-2, AKT, MEK/ERK, human umbilical vein endothelial cells (HUVECs) determined by western blotting and kinase activity assay in VEGF-stimulated HUVECs after treatment with kaempferol. The present study revealed that kaempferol may possess angiogenic inhibition through regulation of VEGF/VEGFR-2 and its downstream signaling cascades (PI3K/AKT, MEK and ERK) in VEGF-stimulated endothelial cells.

\section{Introduction}

Anti-angiogenesis is becoming a very promising goal for cancer therapy $(1,2)$. Angiogenesis is a new passageway from pre-existing blood vessels and an essential step involved in physiological and tumor pathological processes $(1,3)$. Tumor cell growth and metastases processes depend on the induction of a satisfactory blood support $(1,4)$. Many chemotherapeutic agents such as paclitaxel (Taxol) inhibit tumor cell growth, proliferation and induce apoptotic cell death in cancer treatment. Furthermore, the blocking of angiogenesis provides a novel therapeutic target against tumor cells $(5,6)$. In clinical anti-angiogenic therapy, bevacizumab (Avastin) is a monoclonal antibody for anti-vascular endothelial growth factor (VEGF) that counteracts the action of VEGF and inhibits tumor angiogenesis $(7,8)$. Numerous phytochemicals, such as curcumin or epigallocatechin-3-gallate (EGCG) have been demonstrated to exert anti-angiogenic bioactivities in several in vitro and in vivo models (9-11). Thus, identification of phytochemicals with non-cytotoxic effects on normal cells and effective anti-angiogenic action could be of great clinical significance (11-13). 
Kaempferol is a flavonoid phytochemical found in fruits and vegetables and in some traditional Chinese medicines (TCM) (14-16). Kaempferol has been reported to exert biological activities such as anti-inflammatory $(17,18)$, antioxidant $(19,20)$, cardioprotective (19) and antitumor (21-23). Kaempferol has been demonstrated to provide chemopreventive effects on different tumor systems including tumor initiation, promotion, and progression $(24,25)$. Recently, our previous study revealed that kaempferol caused endoplasmic reticulum stress and mitochondria-dependent apoptosis in human osteosarcoma U-2 OS cells (26) and triggered AMPK and AKT-dependent autophagic cell death in human hepatocarcinoma SK-HEP-1 cells (27). In addition, we also demonstrated that kaempferol suppressed U-2 OS cell metastasis through suppression of the ERK/p38/JNK and AP-1 signaling pathways (28). In an anti-angiogenic study, our earlier research indicated that kaempferol induced ROS-mediated p53/ATM-dependent apoptosis in human umbilical vein endothelial cells (HUVECs) (29). However, there is no available information regarding the possible major target and anti-angiogenic mechanism of kaempferol in endothelial cells. In the present study, we analyzed the anti-angiogenic effects of kaempferol on HUVECs. Our results demonstrated that kaempferol inhibited HUVEC proliferation, migration and tube formation. The molecular levels indicated that kaempferol suppressed VEGF receptor-2 (VEGFR-2) expression and its downstream signaling cascades (AKT/mTOR and $\mathrm{MEK} / \mathrm{ERK}$ ) in HUVECs.

\section{Materials and methods}

Chemicals and reagents. Kaempferol, 3-(4,5-dimethylthiazol-2-yl)-2,5-diphenyltetrazolium bromide (MTT), vascular endothelial growth factor (VEGF), the other chemicals and reagents were purchased from Sigma-Aldrich (St. Louis, MO, USA) unless otherwise stated. Medium 200, Low Serum Growth Supplement (LSGS) and Trypsin-EDTA were obtained from Thermo Fisher Scientific, Inc. (Carlsbad, CA, USA). The primary antibodies [VEGFR-2 (cat. no. sc-504), PI3K (cat. no. sc-1637), p-AKT (Ser473) (cat. no. sc-7985-R), AKT (cat.no.sc-1618),p-mTOR (Ser2448) (cat.no.sc-101738), mTOR (cat.no. sc-8319), p-MEK1/2 (Ser218/Ser222) (cat. no. sc-7995), MEK1/2 (cat. no. sc-436), p-ERK (Thr202/Tyr204) (cat. no. sc-16982), ERK (cat. no. sc-135900) and $\beta$-actin (cat. no. sc-47778)] and secondary antibodies against goat anti-mouse (cat. no. sc-2005)/-rabbit (cat. no. sc-2004) and mouse anti-goat (cat. no. sc-2354) immunoglobulin (IgG)-horseradish peroxidase (HRP) were obtained from Santa Cruz Biotechnology (Santa Cruz, CA, USA).

Cell culture. HUVECs were obtained from the Bioresources Collection and Research Center (BCRC), Food Industry Research and Development Institute (Hsinchu, Taiwan). The cells were cultured in Medium 200 and LSGS in a humidified atmosphere containing $5 \% \mathrm{CO}_{2}$ and $95 \%$ air at $37^{\circ} \mathrm{C}$. The cells were applied within the second to fifth passages, and all assays performed used the same culture media with $50 \mathrm{ng} / \mathrm{ml}$ VEGF.

Cytotoxic assay. VEGF-stimulated HUVECs (1x10 $10^{4}$ cells/100 $\mu \mathrm{l} /$ well) were seeded into 96 -well microplates and then incubated with or without $50,100,150$ and $200 \mu \mathrm{M}$ of kaempferol for $24 \mathrm{~h}$. Cell viability was detected by MTT assay as previously described (27,28). Briefly, as soon as kaempferol exposure was completed, $10 \mu \mathrm{l}$ MTT solution $(5 \mathrm{mg} / \mathrm{ml})$ was added to each well, and the plate was incubated for an additional $3 \mathrm{~h}$. The purple crystals were dissolved with the addition of $100 \mu 1$ DMSO. The optical density ratio was assessed spectrophotometrically at $570 \mathrm{~nm}$. The percentage of cell viability at each concentration relative to the untreated control group (\% of control) was plotted.

Wound healing migration assay. HUVECs were plated into 6 -well plates and incubated to $90 \%$ confluence for $24 \mathrm{~h}$. A linear wound was scratched using a $200-\mu 1$ pipette tip through the monolayer before cellular debris was removed. Then, VEGF-stimulated HUVECs were exposed to 50, 100, 150 and $200 \mu \mathrm{M}$ of kaempferol for $24 \mathrm{~h}$. The healing process was captured using a phase-contract microscope after the wound was introduced prior to kaempferol incubation. Cell migration was determined from the images of five random fields. The gap size was analyzed by NIH ImageJ version 1.46 for Windows between the migrating cells from the opposing wound edge, and the data were expressed as the $\%$ of the initial gap size as previously described $(30,31)$.

Boyden chamber Transwell assay. Cell invasion ability was detected as previously described $(31,32)$. The Transwell (Millicell Cell Culture Insert; EMD Millipore, Billerica, MA, USA) with 8- $\mu \mathrm{m}$ polycarbonate filters was used after being pre-coated with Matrigel $(2 \mathrm{mg} / \mathrm{ml}, 20 \mu \mathrm{l}$; BD Biosciences, Bedford, MA, USA) for $2 \mathrm{~h}$ at room temperature. VEGF-stimulated HUVECs $\left(4 \times 10^{3}\right.$ cells $/ 0.4 \mathrm{ml}$ culture medium) were seeded onto the upper compartment prior to 50, 100, 150 and $200 \mu \mathrm{M}$ of kaempferol treatment for $24 \mathrm{~h}$. The cells were then fixed with $4 \%$ paraformaldehyde in PBS and then stained with $2 \%$ crystal violet. The invading cells were counted under a light microscope before quantification with NIH ImageJ version 1.46 for Windows.

Tube formation assay. HUVECs were placed at a density of $5 \times 10^{4}$ cells/well into 24-well flat-bottomed plates after Matrigel (BD Biosciences) pre-coating at $37^{\circ} \mathrm{C}$ for $30 \mathrm{~min}$. The VEGF-stimulated HUVECs $\left(5 \times 10^{4}\right.$ cells $)$ thereafter were treated with or without 50,100,150 and $200 \mu \mathrm{M}$ of kaempferol for $24 \mathrm{~h}$. After exposure, HUVEC tube or network formation was evaluated using a phase-contrast microscope as previously described $(33,34)$.

VEGFR-2, AKT and ERK1/2 kinase assay. VEGF-stimulated HUVECs $\left(5 \times 10^{6}\right.$ cells/75T flask) were incubated with or without 50,100, 150 and $200 \mu \mathrm{M}$ of kaempferol. After incubation for $6 \mathrm{~h}$, the cells were lysed, and the activity of VEGFR-2, AKT and ERK1/2 kinase was determined in accordance with the manufacturer's instructions provided in the AKT Kinase Assay kit (Nonradioactive), the p44/42 MAP Kinase Assay kit (Nonradioactive) and the HTScan VEGF Receptor 2 Kinase Assay kit, respectively (Cell Signaling Technology, Inc., Danvers, MA, USA). Consequently, the purified samples were loaded on $12 \%$ SDS-PAGE to detect targeting proteins by immunoblotting analysis as previously described $(35,36)$. 


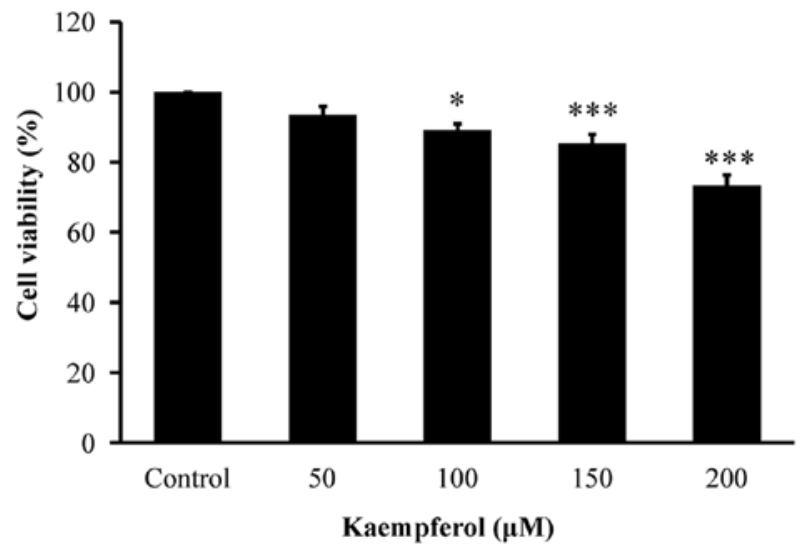

Figure 1. Kaempferol inhibits cell viability in VEGF-stimulated HUVECs. Cells were treated with $50,100,150$ or $200 \mu \mathrm{M}$ of kaempferol for $24 \mathrm{~h}$ and then viability was determined using the MTT assay. Data are plotted as the means $\pm \mathrm{SD}(\mathrm{n}=3) .{ }^{*} \mathrm{P}<0.05$ and ${ }^{* * *} \mathrm{P}<0.001$ vs. the untreated control.

Western blot analysis. VEGF-stimulated HUVECs (5x10 $10^{6}$ cells/75T flask) were exposed to 50,100 and $200 \mu \mathrm{M}$ of kaempferol for $6 \mathrm{~h}$. After being harvested and lysed, the protein concentration was assessed with the Bio-Rad Protein Assay kit (Bio-Rad Laboratories, Inc., Hercules, CA, USA). Quantified protein lysates $(40 \mu \mathrm{g})$ were subjected to 10-12\% SDS-polyacrylamide electrophoresis (SDS-PAGE) gels to separate protein extracts as detailed by our previous studies $(37,38)$. The primary antibodies (VEGFR-2, PI3K, p-AKT, AKT, p-mTOR, mTOR, p-MEK1/2, MEK1/2, p-ERK and ERK, at 1:1,000 dilution) were hybridized overnight at $4^{\circ} \mathrm{C}$, followed by the appropriate HRP-conjugated secondary antibodies (1:5,000 dilution) that were used before the electrochemiluminescence (ECL) reagent (Immobilon Western HRP substrate kit; Merck Millipore, Temecula, CA, USA). The densitometric quantification of each blot was carried out using NIH ImageJ 1.46 software.

Statistical analysis. The data are presented as the means \pm standard deviation (SD) from at least three separate experiments. Statistical data was analyzed using Student's t-test, and statistical significance was considered to be $\mathrm{P}<0.05$ and $\mathrm{P}<0.001$.

\section{Results}

Kaempferol reduces HUVEC viability. First, VEGF-stimulated HUVECs after 0, 50, 100, 150 and $200 \mu \mathrm{M}$ of kaempferol exposure for $24 \mathrm{~h}$ were assessed for growth inhibition and cytotoxicity. Our results indicated that kaempferol significantly decreased viable VEGF-stimulated HUVECs, and this effect was in a concentration- dependent manner (Fig. 1).

Kaempferol inhibits cell migration and invasion, as well as disrupts tube formation in VEGF-stimulated HUVECs. To explore the anti-angiogenic effects of kaempferol in vitro, its inhibitory influences on VEGF-induced tube formation and migration were investigated. Our data demonstrated that kaempferol concentration-dependently suppressed cell migration as determined by wound healing assay (Fig. 2A and B).
A
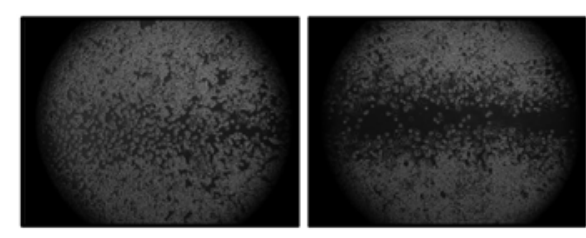

Control

Kaempferol $(150 \mu \mathrm{M})$

B

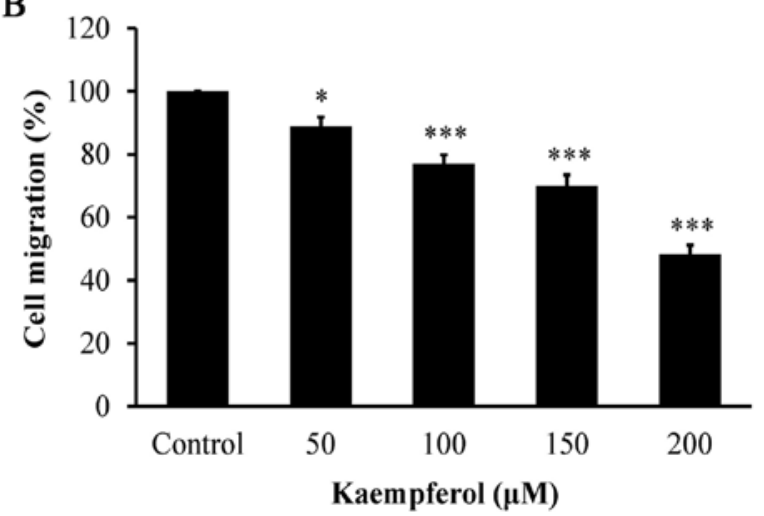

Figure 2. Kaempferol suppresses migratory potential of VEGF-stimulated HUVECs in vitro. (A) Images of the wound healing assay (x100, magnification) were performed after confluent monolayers were wounded. The wounded monolayer was incubated with 50, 100, 150 and $200 \mu \mathrm{M}$ of kaempferol for $24 \mathrm{~h}$. (B) Migration distances were quantified with ImageJ software. Each bar represents the mean \pm SD in triplicate. ${ }^{*} \mathrm{P}<0.05$ and ${ }^{* * *} \mathrm{P}<0.001$ vs. the VEGF-treated only control.

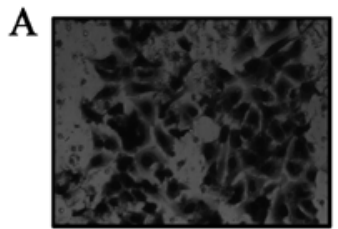

Control

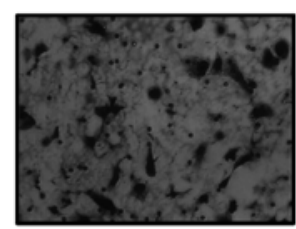

Kaempferol $(150 \mu \mathrm{M})$
B

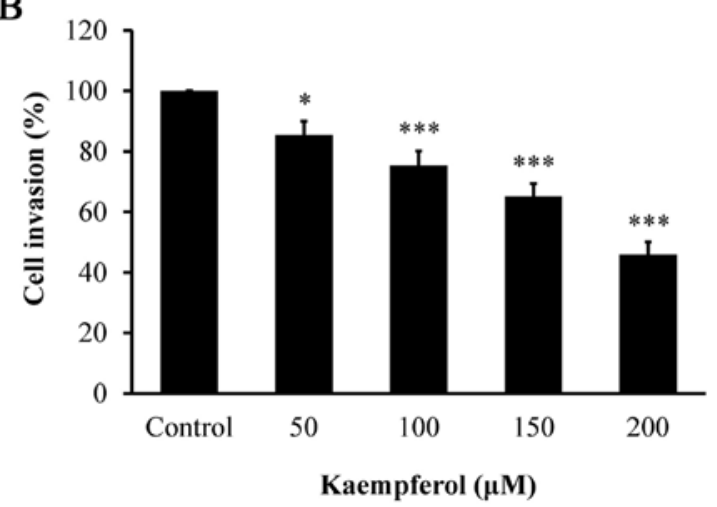

Figure 3. Kaempferol reduces VEGF-stimulated HUVEC invasion in vitro. (A) Effects of kaempferol treatment on the invasive ability of VEGF-stimulated HUVECs were analyzed by a Boyden chamber assay. (B) The number of invading cells was assessed as mentioned in Materials and methods. Each bar is representative of the mean $\pm \mathrm{SD}$ of three independent samples for each treatment. ${ }^{*} \mathrm{P}<0.05$ and ${ }^{* * * *} \mathrm{P}<0.001$ vs. the VEGF-treated only control.

Kaempferol also significantly suppressed cell invasion (Fig. 3A and B) in a concentration-dependent manner. 
A

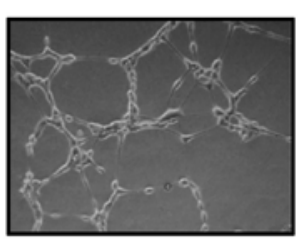

Control

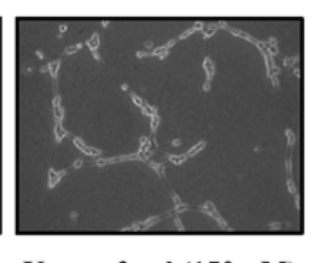

Kaempferol $(150 \mu \mathrm{M})$

B

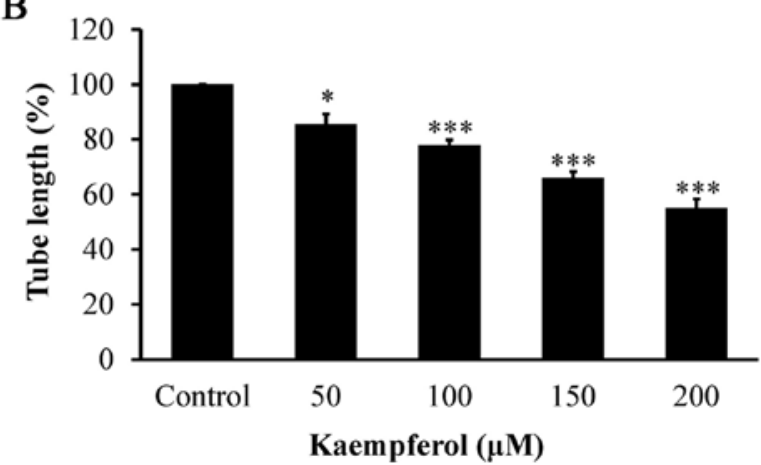

Figure 4. Kaempferol inhibits capillary-structure formation of VEGF-stimulated HUVECs. (A) The inhibitory effect of kaempferol on capillary tube formation in VEGF-stimulated HUVECs with Matrigel was assessed. (B) The level of tube length was detected as mentioned in Materials and methods. Each bar is representative of the mean \pm SD of three independent samples for each treatment. ${ }^{*} \mathrm{P}<0.05$ and $^{* * * *} \mathrm{P}<0.001$ vs. the VEGF-treated only control.

A

\begin{tabular}{rcccc} 
& \multicolumn{4}{c}{ Kaempferol $(\boldsymbol{\mu} \mathbf{M})$} \\
\cline { 2 - 5 } VEGFR-2 & 0 & 50 & 100 & 200 \\
\cline { 2 - 5 } & & & & \\
\cline { 2 - 5 }$\beta$-actin & 1.0 & 0.9 & 0.5 & 0.2 \\
\cline { 2 - 4 } & & & & \\
\cline { 2 - 4 } & & & &
\end{tabular}

B

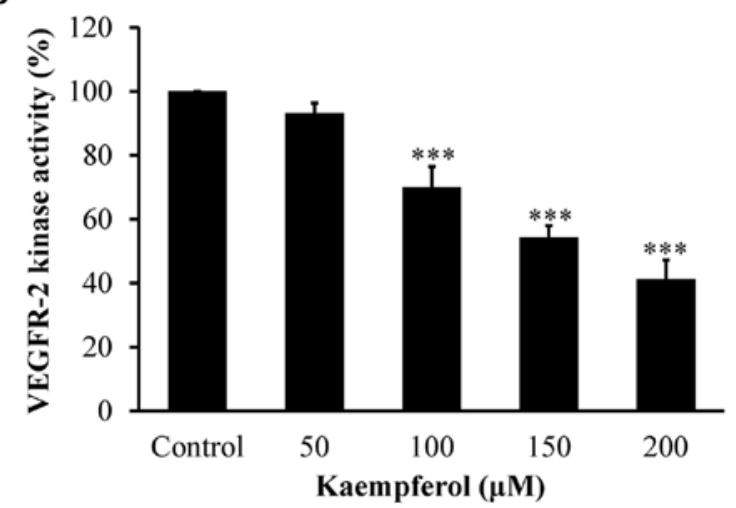

Figure 5. Kaempferol suppresses VEGFR-2 signaling in VEGF-stimulated HUVECs. (A) Cells were treated with 50, 100 and $200 \mu \mathrm{M}$ of kaempferol for $6 \mathrm{~h}$. Cells were then harvested, and the protein expression levels of associated VEGFR-2 were illustrated by western blot analysis. $\beta$-actin was employed as an internal control. (B) Cells were treated for $6 \mathrm{~h}$ and VEGFR-2 kinase activity was assessed as described in Materials and methods. The quantification of the data was performed, and the results represent the means \pm SD $(\mathrm{n}=3) .{ }^{* * *} \mathrm{P}<0.001$ vs. the control.

To detect tube formation by endothelial cells, kaempferol at 50,100,150 and $200 \mu \mathrm{M}$ was added for $24 \mathrm{~h}$. The results
A

\begin{tabular}{|c|c|c|c|c|}
\hline & & Kaempf & $\operatorname{erol}(\mu)$ & \\
\hline & 0 & 50 & 100 & 200 \\
\hline PI3K & $\longrightarrow$ & $=$ & $=$ & $=$ \\
\hline & 1.0 & 0.7 & 0.6 & 0.3 \\
\hline p-AKT & 3 & $\infty$ & $\infty$ & $=$ \\
\hline & 1.0 & 0.9 & 0.7 & 0.6 \\
\hline AKT & 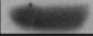 & & 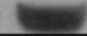 & $\mathrm{E}$ \\
\hline & 1.0 & 1.0 & 1.0 & 1.0 \\
\hline p-mTOR & Socess & sin & sins & $\cdots$ \\
\hline & 1.0 & 0.9 & 0.7 & 0.3 \\
\hline mTOR & & & $=$ & 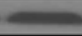 \\
\hline & 1.0 & 1.0 & 1.0 & 1.0 \\
\hline acti & & & & \\
\hline
\end{tabular}

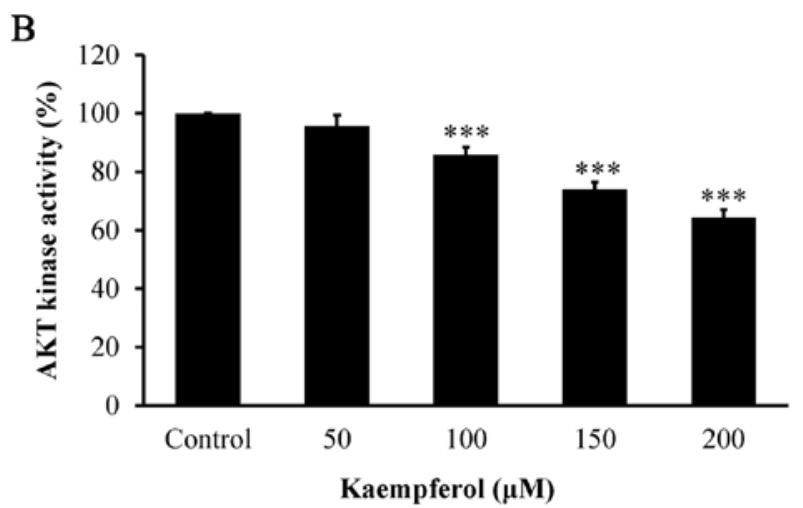

Figure 6. Kaempferol alters abundance of PI3K/AKT/mTOR signaling and inhibits AKT kinase activity in HUVECs. (A) Cells were exposed to 50, 100 and $200 \mu \mathrm{M}$ of kaempferol for $6 \mathrm{~h}$. Cells were then harvested and lysed before the levels of PI3K, p-AKT (Ser473), AKT, p-mTOR (Ser2448) and mTOR were detected by western blot analysis. $\beta$-actin was employed as an internal control. (B) Cells were incubated with kaempferol for $6 \mathrm{~h}$, and AKT kinase activity was assessed. The results represent the the means $\pm S D(n=3)$. ${ }^{* * * *} \mathrm{P}<0.001$ vs. the control.

revealed that kaempferol markedly disrupted the tube-like structures and network formation (Fig. 4A and B), and this effect was concentration-dependent. Therefore, we determined that kaempferol exhibits anti-angiogenic effects on VEGF-stimulated HUVECs in vitro.

Kaempferol suppresses VEGFR-2 signaling in VEGFstimulated HUVECs. To clarify whether the angiogenic suppression requires VEGFR-2 signaling in kaempferol-treated HUVECs, the level of VEGFR-2 was detected. The protein level of VEGFR-2 (Fig. 5A) and kinase activity (Fig. 5B) were markedly suppressed by kaempferol exposure in a concentration-dependent manner. Our data demonstrated that kaempferol-inhibited angiogenesis may be involved in VEGFR-2 signaling in VEGF-stimulated HUVECs.

Kaempferol alters abundance of PI3K/AKT/mTOR signaling in VEGF-stimulated HUVECs. To determine the major pathway involved in the anti-angiogenic effect of kaempferol, we detected PI3K/AKT/mTOR signaling after kaempferol treatment at $6 \mathrm{~h}$. Our results indicated that the protein levels of PI3K, and phosphorylation of both AKT and mTOR were significantly decreased in a concentration-dependent manner (Fig. 6A). The results revealed that PI3K/AKT/mTOR 
A

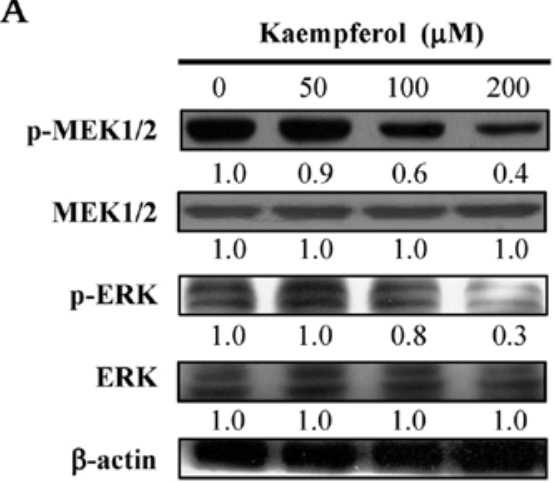

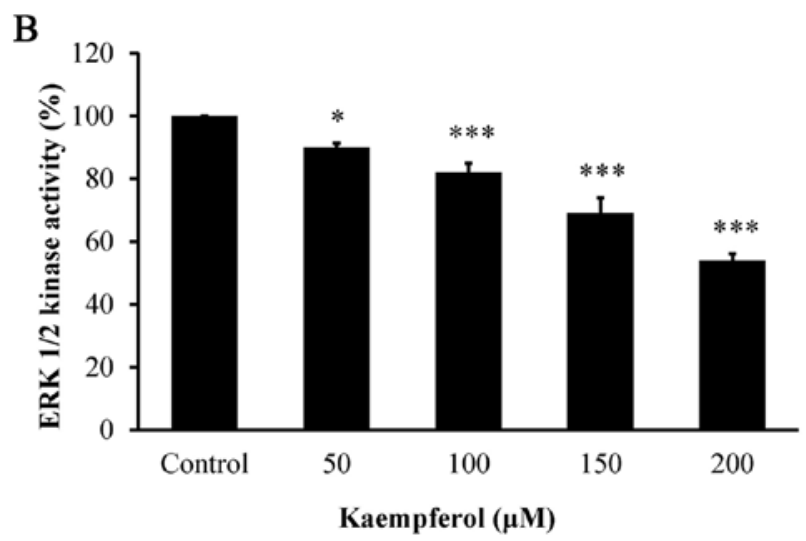

Figure 7. Kaempferol downregulates the levels of MEK and ERK signaling and suppresses ERK kinase activity in HUVECs. (A) Cells were exposed to 50, 100 and $200 \mu \mathrm{M}$ of kaempferol for $6 \mathrm{~h}$. The protein expression levels [p-MEK1/2 (Ser218/Ser222), MEK1/2, p-ERK (Thr202/Tyr204) and ERK] were revealed using immunoblotting analysis. $\beta$-actin was used as an internal control. (B) Cells were treated with kaempferol for $6 \mathrm{~h}$, and ERK1/2 kinase activity was assessed. The results represent the means $\pm \mathrm{SD}(\mathrm{n}=3)$. ${ }^{*} \mathrm{P}<0.05$ and ${ }^{* * *} \mathrm{P}<0.001$ vs. the control.

signaling contributed to the kaempferol-induced angiogenic effects on VEGF-stimulated HUVECs.

Kaempferol affects the protein levels of phosphorylation of MEK and ERK signaling in VEGF-stimulated HUVECs. We next aimed to clarify whether kaempferol-induced anti-angiogenesis in HUVECs was mediated mainly through phosphorylation of the MEK and ERK pathways. To demonstrate this, we further investigated the protein levels of phosphorylated MEK and phosphorylated ERK and determined that both were significantly decreased in a concentration-dependent manner after kaempferol exposure (Fig. 7A). The finding demonstrated that kaempferol attenuated angiogenesis on VEGF-stimulated HUVECs through the MEK1/2 and ERK pathways.

Kaempferol inhibits AKTandERK kinases in VEGF-stimulated HUVECs. To determine whether AKT and ERK activities are involved in HUVECs, we assessed the kinase activities of AKT and ERK. AKT kinase (Fig. 6B) and ERK1/2 kinase (Fig. 7B) activities were concentration-dependently suppressed by kaempferol exposure. Therefore, we provide direct evidence that kaempferol inhibited angiogenic effects by blocking AKT and ERK signaling in VEGF-stimulated HUVECs.

\section{Discussion}

Flavonoids are important phytochemicals found in foods like fruits, vegetables, wine and tea (14-16,39). Notably, kaempferol is a flavonoid phytochemical, which exists in a variety of fruits and vegetables, including onions, kale, broccoli, apples, cherries, berries, tea and red wine $(40,41)$. Kaempferol has multiple bioactivities, including antitumor effects, an antioxidant activity, and an anti-inflammatory function (17-20). In addition, kaempferol has induced apoptotic and autophagic cell death and/or cell cycle arrest in various tumor cell lines, including colon, liver, gastric and bladder cancer cells $(25,27,42-47)$. Kim et al (48) first demonstrated that kaempferol modulated angiogenesis and immune-endothelial cell adhesion. Zhao et al (49) revealed that kaempferol from $\mathrm{Pu}$-erh tea had anti-colorectal tumor cells and anti-angiogenesis effects on HUVECs. However, the target and molecular mechanism involved in the anti-angiogenic effects of kaempferol are still unknown. Notably, cell migration, invasion, tube formation and proliferation of endothelial cells are necessary processes during tumor angiogenesis $(1,12,50)$. In the present study, we are the first to report that kaempferol at 50, 100, 150 and $200 \mu \mathrm{M}$ inhibited VEGF-stimulated HUVEC cell proliferation (Fig. 1), inhibited cell migration (Fig. 2) and invasion (Fig. 3), and these effects were vital factors in angiogenic activity. Markedly, kaempferol inhibited tube formation (Fig. 4) in VEGF-stimulated HUVECs. Our results revealed that kaempferol triggered anti-angiogenic activity in VEGF-stimulated HUVECs, and this finding is in agreement with our previous study by our research group (29).

It is well known that vascular endothelial growth factor (VEGF) stimulates VEGF receptor further to activate its kinase activity which is a serious step in initiated tumor angiogenesis (51). Suppression of angiogenesis through the blocking of the VEGF/VEGFR signaling pathway has developed as a potential approach in antitumor therapy $(51,52)$. VEGFR family members include KDR (kinase insert domain-containing receptor; VEGFR-2), FLT1 (Fms-like tyrosine kinase; VEGFR-1), and FLT4 (VEGFR-3) (51). VEGFR-2 binds VEGF-A, which is expressed in vascular endothelial cells and hematopoietic stem cells (53). In the present study, we focused on VEGFR-2 and its downstream signaling in kaempferol-treated HUVECs. Our results demonstrated that kaempferol triggered anti-angiogenic activity in VEGF-stimulated HUVECs by decreasing the VEGFR-2 protein level (Fig. 5A) and kinase activity (Fig. 5B). It has been documented that Y1175 and Y1214 in human VEGFR-2 are the main auto-phosphorylation sites following VEGF binding, and the activation of several downstream pathways, including PI3K/AKT and MEK/ERK levels $(54,55)$. Our results revealed that kaempferol also reduced VEGFR-2 downstream protein levels, including PI3K, p-AKT, p-mTOR (Fig. 6A) and p-MEK1/2, p-ERK1/2 signaling (Fig. 7A). In addition, kaempferol also reduced AKT and ERK1/2 kinase activity (Figs. 6B and 7B). Our findings revealed that the kaempferol-inhibited angiogenic effects on VEGF-stimulated HUVECs may require VEGR-2 signaling.

In conclusion, these data clearly revealed the molecular signaling pathway in VEGF-stimulated HUVECs induced by kaempferol as summarized in Fig. 8. These findings provide 


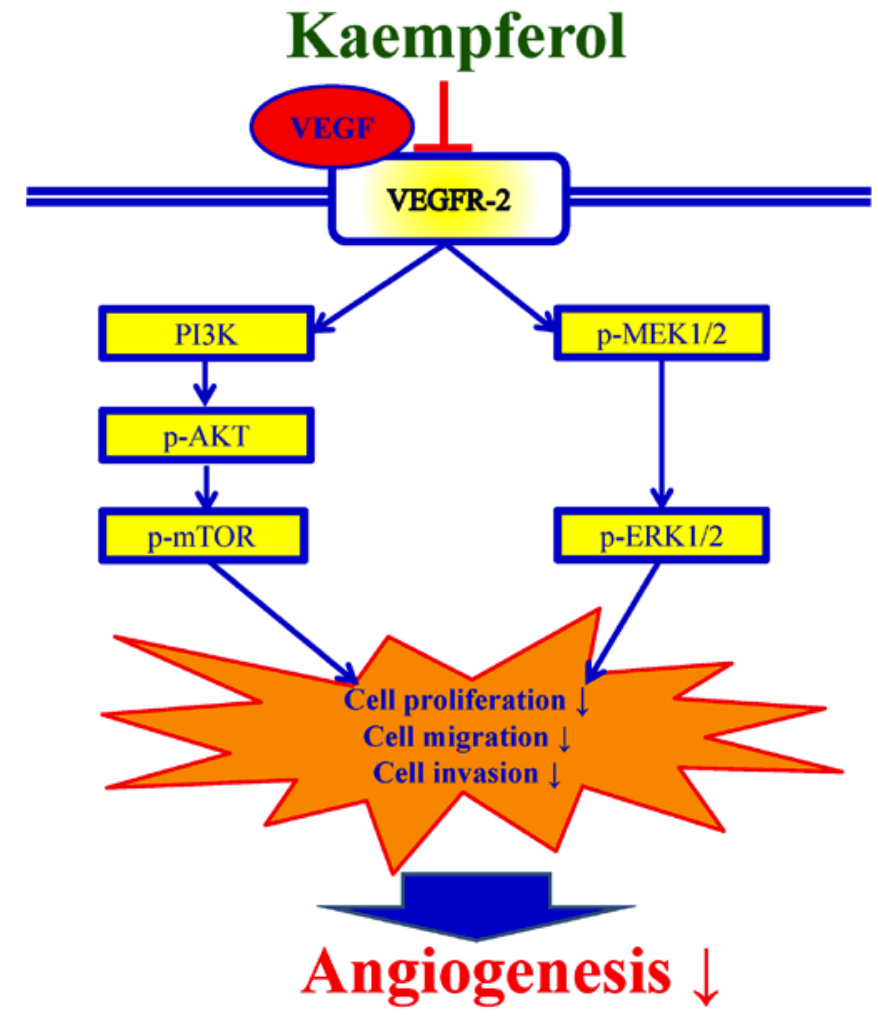

Figure 8. A model describing the molecular mechanism of kaempferol on the anti-angiogenic activity of VEGF-stimulated HUVECs.

evidence demonstrating the anti-angiogenic activity of kaempferol, and we suggest that kaempferol which is a phytochemical may act as an angiogenesis inhibitor for cancer treatment in the near future.

\section{Acknowledgements}

Not applicable.

\section{Funding}

The present study was financially supported by a research grant from the Kaohsiung Armed Forces General Hospital (Kaohsiung, Taiwan).

\section{Availability of data and materials}

The datasets used during the present study are available from the corresponding author upon reasonable request.

\section{Authors' contributions}

HKC, CTH, PCS and JSY conceived and designed the experiments. HKC, CTH, YSL and CCL performed the experiments. CYS, PSC, HYC and FJT analyzed the data. HKC, CTH, PCS, JSY and CCL wrote the paper and performed all the necessary modifications to the manuscript. All authors read, approved the final manuscript and agreed to be accountable for all aspects of the research in ensuring that the accuracy or integrity of any part of the work are appropriately investigated and resolved.

\section{Ethics approval and consent to participate}

Not applicable.

\section{Consent for publication}

Not applicable.

\section{Competing interests}

The authors declare that they have no competing interests.

\section{References}

1. Varinska L, Kubatka P, Mojzis J, Zulli A, Gazdikova K, Zubor P, Büsselberg D, Caprnda M, Opatrilova R, Gasparova I, et al: Angiomodulators in cancer therapy: New perspectives. Biomed Pharmacother 89: 578-590, 2017.

2. Aalders KC, Tryfonidis K, Senkus E and Cardoso F: Anti-angiogenic treatment in breast cancer: Facts, successes, failures and future perspectives. Cancer Treat Rev 53: 98-110, 2017.

3. Markowska A, Sajdak S, Markowska J and Huczyński A: Angiogenesis and cancer stem cells: New perspectives on therapy of ovarian cancer. Eur J Med Chem 142: 87-94, 2017.

4. Lupo G, Caporarello N, Olivieri M, Cristaldi M, Motta C, Bramanti V, Avola R, Salmeri M, Nicoletti F and Anfuso CD: Anti-angiogenic therapy in cancer: Downsides and new pivots for precision medicine. Front Pharmacol 7: 519, 2017.

5. Ai B, Bie Z, Zhang S and Li A: Paclitaxel targets VEGF-mediated angiogenesis in ovarian cancer treatment. Am J Cancer Res 6: 1624-1635, 2016.

6. Allegrini G, Coltelli L, Orlandi P, Fontana A, Camerini A Ferro A, Cazzaniga M, Casadei V, Lucchesi S, Bona E, et al: Pharmacogenetic interaction analysis of VEGFR-2 and IL-8 polymorphisms in advanced breast cancer patients treated with paclitaxel and bevacizumab. Pharmacogenomics 15: 1985-1999, 2014.

7. Sini V, Cassano A, Corsi D, De Laurentiis M, Gamucci T, Mauri M, Naso G, Roselli M, Ruggeri EM, Tonini G, et al: Bevacizumab as first-line treatment in HER2-negative advanced breast cancer: Pros and cons. Tumori 102: 472-480, 2016.

8. Pentheroudakis G, Kotoula V, Kouvatseas G, Charalambous E, Dionysopoulos D, Zagouri F, Koutras A, Papazisis K, Pectasides D, Samantas E, et al: Association of VEGF-A splice variant mRNA expression with outcome in bevacizumab-treated patients with metastatic breast cancer. Clin Breast Cancer 14: 330-338, 2014.

9. Abd El-Rahman SS, Shehab G and Nashaat H: Epigallocatechin-3-Gallate: The prospective targeting of cancer stem cells and preventing metastasis of chemically-induced mammary cancer in rats. Am J Med Sci 354: 54-63, 2017.

10. Walczak K, Marciniak S and Rajtar G: Cancer chemoprevention-selected molecular mechanisms. Postepy Hig Med Dosw 71: 149-161, 2017.

11. Saberi-Karimian M, Katsiki N, Caraglia M, Boccellino M, Majeed M and Sahebkar A: Vascular endothelial growth factor: An important molecular target of curcumin. Crit Rev Food Sci Nutr: 1-14, 2017.

12. Bhattacharjee S and Mandal DP: Angiogenesis modulation: The 'spice effect'. J Environ Pathol Toxicol Oncol 31: 273-283, 2012.

13. Wang S, Shen P, Zhou J and Lu Y: Diet phytochemicals and cutaneous carcinoma chemoprevention: A review. Pharmacol Res 119: 327-346, 2017.

14. Kilari EK and Putta S: Biological and phytopharmacological descriptions of litchi chinensis. Pharmacogn Rev 10: 60-65, 2016.

15. Chen AY and Chen YC: A review of the dietary flavonoid, kaempferol on human health and cancer chemoprevention. Food Chem 138: 2099-2107, 2013.

16. Murakami A and Ohnishi K: Target molecules of food phytochemicals: Food science bound for the next dimension. Food Funct 3: 462-476, 2012.

17. Zhang R, Ai X, Duan Y, Xue M, He W, Wang C, Xu T, Xu M, Liu B, Li C, et al: Kaempferol ameliorates H9N2 swine influenza virus-induced acute lung injury by inactivation of TLR4/MyD88-mediated NF- $\mathrm{BB}$ and MAPK signaling pathways. Biomed Pharmacother 89: 660-672, 2017. 
18. Zhuang Z, Ye G and Huang B: Kaempferol alleviates the interleukin-1 $\beta$-induced inflammation in rat osteoarthritis chondrocytes via suppression of NF- $\kappa \mathrm{B}$. Med Sci Monit 23: 3925-3931, 2017

19. Duan L, Ding W, Liu X, Cheng X, Cai J, Hua E and Jiang H: Biosynthesis and engineering of kaempferol in Saccharomyces cerevisiae. Microb Cell Fact 16: 165, 2017.

20. Han S, Hanh Nguyen TT, Hur J, Kim NM, Kim SB, Hwang KH, Moon YH, Kang C, Chung B, Kim YM, et al: Synthesis and characterization of novel astragalin galactosides using $\beta$-galactosidase from Bacillus circulans. Enzyme Microb Technol 103: 59-67, 2017.

21. Hung TW, Chen PN, Wu HC, Wu SW, Tsai PY, Hsieh YS and Chang HR: Kaempferol inhibits the invasion and migration of renal cancer cells through the downregulation of AKT and FAK pathways. Int J Med Sci 14: 984-993, 2017.

22. Kashafi E, Moradzadeh M, Mohamadkhani A and Erfanian S: Kaempferol increases apoptosis in human cervical cancer HeLa cells via PI3K/AKT and telomerase pathways. Biomed Pharmacother 89: 573-577, 2017.

23. Lee GA, Choi KC and Hwang KA: Kaempferol, a phytoestrogen, suppressed triclosan-induced epithelial-mesenchymal transition and metastatic-related behaviors of MCF-7 breast cancer cells. Environ Toxicol Pharmacol 49: 48-57, 2017.

24. Okoye FB, Sawadogo WR, Sendker J, Aly AH, Quandt B, Wray V, Hensel A, Esimone CO, Debbab A, Diederich M and Proksch P: Flavonoid glycosides from Olax mannii: Structure elucidation and effect on the nuclear factor kappa B pathway. J Ethnopharmacol 176: 27-34, 2015.

25. Song W, Dang Q, Xu D, Chen Y, Zhu G, Wu K, Zeng J, Long Q Wang X, He D and Li L: Kaempferol induces cell cycle arrest and apoptosis in renal cell carcinoma through EGFR/p38 signaling. Oncol Rep 31: 1350-1356, 2014.

26. Huang WW, Chiu YJ, Fan MJ, Lu HF, Yeh HF, Li KH, Chen PY, Chung JG and Yang JS: Kaempferol induced apoptosis via endoplasmic reticulum stress and mitochondria-dependent pathway in human osteosarcoma U-2 OS cells. Mol Nutr Food Res 54: $1585-1595,2010$.

27. Huang WW, Tsai SC, Peng SF, Lin MW, Chiang JH, Chiu YJ, Fushiya S, Tseng MT and Yang JS: Kaempferol induces autophagy through AMPK and AKT signaling molecules and causes $\mathrm{G} 2 / \mathrm{M}$ arrest via downregulation of CDK1/cyclin B in SK-HEP-1 human hepatic cancer cells. Int J Oncol 42: 2069-2077, 2013.

28. Chen HJ, Lin CM, Lee CY, Shih NC, Peng SF, Tsuzuki M, Amagaya S, Huang WW and Yang JS: Kaempferol suppresses cell metastasis via inhibition of the ERK-p38-JNK and AP-1 signaling pathways in U-2 OS human osteosarcoma cells. Oncol Rep 30: 925-932, 2013.

29. Lee CF, Yang JS, Tsai FJ, Chiang NN, Lu CC, Huang YS, Chen C and Chen FA: Kaempferol induces ATM/p53-mediated death receptor and mitochondrial apoptosis in human umbilical vein endothelial cells. Int J Oncol 48: 2007-2014, 2016.

30. Yang JS, Lin CA, Lu CC, Wen YF, Tsai FJ and Tsai SC: Carboxamide analog ITR-284 evokes apoptosis and inhibits migration ability in human lung adenocarcinoma A549 cells Oncol Rep 37: 1786-1792, 2017.

31. Tsai SC, Tsai MH, Chiu CF, Lu CC, Kuo SC, Chang NW and Yang JS: AMPK-dependent signaling modulates the suppression of invasion and migration by fenofibrate in CAL 27 oral cancer cells through NF- $\mathrm{BB}$ pathway. Environ Toxicol 31: 866-876, 2016.

32. Goodwin CR, Lal B, Zhou X, Ho S, Xia S, Taeger A, Murray J and Laterra J: Cyr61 mediates hepatocyte growth factor-dependent tumor cell growth, migration, and Akt activation. Cancer Res 70: 2932-2941, 2010

33. Lu CC, Chen HP, Chiang JH, Jin YA, Kuo SC, Wu TS, Hour MJ, Yang JS and Chiu YJ: Quinazoline analog HMJ-30 inhibits angiogenesis: Involvement of endothelial cell apoptosis through ROS-JNK-mediated death receptor 5 signaling. Oncol Rep 32: 597-606, 2014.

34. Chiang JH, Yang JS, Lu CC, Hour MJ, Chang SJ, Lee TH and Chung JG: Newly synthesized quinazolinone HMJ-38 suppresses angiogenetic responses and triggers human umbilical vein endothelial cell apoptosis through p53-modulated Fas/death receptor signaling. Toxicol Appl Pharmacol 269: 150-162, 2013.

35. FujitaH,Gomori A,Fujioka Y,Kataoka Y, TanakaK, HashimotoA, Suzuki T, Ito K, Haruma T, Yamamoto-Yokoi H, et al: High potency VEGFRs/MET/FMS triple blockade by TAS-115 concomitantly suppresses tumor progression and bone destruction in tumor-induced bone disease model with lung carcinoma cells. PLoS One 11: e0164830, 2016.
36. $\mathrm{Pu} \mathrm{K}$, Yuan L, Chen L, Wang A, Zhou X, Zhang $\mathrm{H}$ and Zhu Y: Identification of VEGFR2-binding peptides using high throughput bacterial display methods and functional assessment. Curr Cancer Drug Targets 15: 158-170, 2015.

37. Yang JS, Hour MJ, Huang WW, Lin KL, Kuo SC and Chung JG: MJ-29 inhibits tubulin polymerization, induces mitotic arrest, and triggers apoptosis via cyclin-dependent kinase 1-mediated Bcl-2 phosphorylation in human leukemia U937 cells. J Pharmacol Exp Ther 334: 477-488, 2010.

38. Lee MR, Lin C, Lu CC, Kuo SC, Tsao JW, Juan YN, Chiu HY, Lee FY, Yang JS and Tsai FJ: YC-1 induces G0/G1 phase arrest and mitochondria-dependent apoptosis in cisplatin-resistant human oral cancer CAR cells. Biomedicine 7: 12, 2017.

39. Davatgaran-Taghipour Y, Masoomzadeh S, Farzaei MH, Bahramsoltani R, Karimi-Soureh Z, Rahimi R and Abdollahi M: Polyphenol nanoformulations for cancer therapy: Experimental evidence and clinical perspective. Int J Nanomedicine 12: 2689-2702, 2017.

40. Liu RH: Health-promoting components of fruits and vegetables in the diet. Adv Nutr 4 (Suppl): S384-S392, 2013.

41. Arif H, Sohail A, Farhan M, Rehman AA, Ahmad A and Hadi SM: Flavonoids-induced redox cycling of copper ions leads to generation of reactive oxygen species: A potential role in cancer chemoprevention. Int J Biol Macromol 106: 569-578, 2018.

42. Choi EJ and Ahn WS: Kaempferol induced the apoptosis via cell cycle arrest in human breast cancer MDA-MB-453 cells. Nutr Res Pract 2: 322-325, 2008.

43. Lee HS, Cho HJ, Yu R, Lee KW, Chun HS and Park JH: Mechanisms underlying apoptosis-inducing effects of Kaempferol in HT-29 human colon cancer cells. Int J Mol Sci 15: 2722-2737, 2014

44. Che J, Liang B, Zhang Y, Wang Y, Tang J and Shi G: Kaempferol alleviates ox-LDL-induced apoptosis by up-regulation of autophagy via inhibiting PI3K/Akt/mTOR pathway in human endothelial cells. Cardiovasc Pathol 31: 57-62, 2017.

45. Varshney R, Gupta S and Roy P: Cytoprotective effect of kaempferol against palmitic acid-induced pancreatic $\beta$-cell death through modulation of autophagy via AMPK/mTOR signaling pathway. Mol Cell Endocrinol 448: 1-20, 2017.

46. Cho IH, Choi YJ, Gong JH, Shin D, Kang MK and Kang YH: Astragalin inhibits autophagy-associated airway epithelial fibrosis. Respir Res 16: 51, 2015.

47. Huang HC, Syu KY and Lin JK: Chemical composition of Solanum nigrum linn extract and induction of autophagy by leaf water extract and its major flavonoids in AU565 breast cancer cells. J Agric Food Chem 58: 8699-8708, 2010.

48. Kim JD, Liu L, Guo W and Meydani M: Chemical structure of flavonols in relation to modulation of angiogenesis and immune-endothelial cell adhesion. J Nutr Biochem 17: 165-176, 2006.

49. Zhao X, Song JL, Kim JD, Lee JS and Park KY: Fermented Pu-erh tea increases in vitro anticancer activities in HT-29 cells and has antiangiogenetic effects on HUVECs. J Environ Pathol Toxicol Oncol 32: 275-288, 2013.

50. Yüksel Ş, Boylu Akyerli C and Cengiz Yakicier M: Angiogenesis, invasion, and metastasis characteristics of hepatocellular carcinoma. J Gastrointest Cancer Aug 7, 2017.

51. Ramjiawan RR, Griffioen AW and Duda DG: Anti-angiogenesis for cancer revisited: Is there a role for combinations with immunotherapy? Angiogenesis 20: 185-204, 2017.

52. Chebib R, Verlingue L, Cozic N, Faron M, Burtin P, Boige V, Hollebecque A and Malka D: Angiogenesis inhibition in the second-line treatment of metastatic colorectal cancer: A systematic review and pooled analysis. Semin Oncol 44: 114-128, 2017.

53. Wu M, Xiong H, Xu Y, Xiong X, Zou H, Zheng M, Wang X and Zhou X: Association between VEGF-A and VEGFR-2 polymorphisms and response to treatment of neovascular AMD with anti-VEGF agents: A meta-analysis. Br J Ophthalmol 101: 976-984, 2017.

54. Li W, Man XY, Li CM, Chen JQ, Zhou J, Cai SQ, Lu ZF and Zheng M: VEGF induces proliferation of human hair follicle dermal papilla cells through VEGFR-2-mediated activation of ERK. Exp Cell Res 318: 1633-1640, 2012.

55. Zhang Z, Neiva KG, Lingen MW, Ellis LM and Nör JE: VEGF-dependent tumor angiogenesis requires inverse and reciprocal regulation of VEGFR1 and VEGFR2. Cell Death Differ 17: 499-512, 2010. 